lacking turbidity, colour and disagreeable taste or odour. Preferably, it should come from well-operated public supply systems conforming with acceptable standards. Samples should be taken at least once weekly from representative points, and the results of bacteriological analysis reported to the airport health and operating authorities and used to determine whether the airport water meets the bacteriological standard, and, if not, what corrective measures are required. The water supply should be inspected by a competent sanitary engineer at least once a year and whenever changes are made in the system that might affect the quality of the water.

If water must be drawn from a supply of inferior or unknown quality for use by crews or passengers, it should be given sufficient treatment to destroy cysts of Entamoeba hystolytica and the virus of infectious hepatitis; all the other disease organisms generally found in contaminated water will be destroyed by this treatment.

Food should be of good sanitary quality, placed in refrigerators as necessary, and kept scrupulously clean. All meat and fish should be thoroughly cooked before serving. In tropical countries infection with Ascaris is widespread, so that raw foods such as green salads and chopped raw vegetables should be avoided. All food should be carefully handled and protected from contamination by insects and other animals, soiled hands, and dirty surfaces. To prevent chemical poisoning, vessels and utensils containing such elements as eadmium and lead should be avoided, the strictest precautions observed regarding the use of poisons around food areas, and only food of the highest quality purchased. Because of the special hazards of foods like cream, milk and milk products, cracked eggs (especially duck's), 'shellfish', gravies and meat salads and dressings, preference should be given to plain, simple foods requiring the minimum of handling. Raw oysters and other shellfish should not be used unless it is certain that they are fresh, uncontaminated, and come from clean areas. Milk and milk products should be sterilized and kept in bottles; and the opened bottles should remain in refrigerators.

Special cleansing and germicidal treatment should be given to dishes and utensils before use.

The guide contains a detailed description of the handling and disposal of toilet wastes, sewage, airsickness containers, and refuse, at airports and on the aircraft. Particular care should be taken to avoid spillage or open exposure, since this leads to fly and rat infestations. If practicable, the final disposal of garbage should be at a point remote from the airport ; if not, it can be burned, buried, or ground and dis. charged into a sewer; open pits or dumps are unsatisfactory because of flies and rats. On aircraft, the provision of watertight receptables, easily cleanable floorings, soil-cans, tanks and wash-basins is important.

Rooms used by crews and passengers in transit at international airports should be effectively mosquitoproofed in areas where mosquitoes and flies are prevalent. Every day, any mosquitoes that may have gained entrance should be destroyed. Walls and ceilings, particularly in sleeping quarters, should be sprayed regularly with residual insecticide, in accordance with the recommendations of the WHO Expert Committee on Insecticides.

To carry out this work, airports must have adequate staff, equipment and premises. The adequacy and efficiency of ground installations are of interest and concern to many groups ; to increase efficiency and co-operation, committees, such as national and local facilitation committees, should review procedures and practices and study possible improvements.

\title{
CENTENARY CELEBRATIONS OF W. M. BAYLISS AND J. S. HALDANE IN MOSCOW
}

A JOINT meeting of the U.S.S.R.-Great Britain Society and the Moscow Physiological Society was recently held at the Friendship House in Moscow. The meeting was devoted to the centenary of the births of W. M. Bayliss and J. S. Haldane.

The meeting was opened by Prof. V. Parin, president of the Physiological Society. Prof. K. Koshtoyants, a prominent Soviet physiologist and head of the Department of Physiology of the Moscow State University, discussed the life and research work of Prof. Bayliss. "Bayliss's name is one of the brightest in the history of world physiology", he said. Among other things, Prof. Koshtoyants said that soon after the Civil War a State Publishing House was set up in the Soviet Union. It planned the publication of a number of major works of world science, and one of the first in the list of these works was Bayliss's famous book "Principles of General Physiology". In 1927, Russian translations of two monographs by Bayliss were published. Prof. Koshtoyants went on to speak of the profound mutual interest in, and respect for, each other of Bayliss and the equally great Russian physiologist Ivan Pavlov. It so happened that Pavlov in Russia and Bayliss and Starling in Britain did parallel research on the regulation of the activity of the pancreas, but came to opposite conclusions. Accord. ing to Pavlov, the gland produced its secretion as a result of nervous signals, whereas according to Bayliss the gland was made to function by an active chemical agent contained in the blood. A thorough joint investigation of the experiments showed that the Russian and the British physiologists were both right, and as a result a comprehensive modern conception of the regulation of pancreatic secretion was formed.

Prof. L. Shik then spoke of the research work done by J. S. Haldane. As a result of Haldane's researches, he said, basic conceptions were formed of the physiology of respiration. Haldane's experiments were distinguished for their remarkable outward simplicity, which was actually the result of a good deal of thought and precise preliminary calculations. Unlike many representatives of the so-called 'pure science', Haldane was interested in the problems of applied physiology, and his research on the physiology of divers and airmen provided scientific grounds for modern practical measures ensuring man's safety in the conditions of changing barometric pressure. Many of his experiments, some of which were quite 
dangerous, he conducted on himself. No wonder that when the well-known Russian physiologist, A. Samoilov, urged young research workers to investigate directly the human organism, he always referred to Haldane's successful experiments.
Some of the members of the U.S.S.R.-Britain Society prepared for the jubilee meeting an exhibit with the portraits of Bayliss and Haldane and a display of Russian translations of their books.

\section{IS HYPERCONJUGATION NECESSARY?}

$\mathbf{M}$ ULLIKEN, Reike and Brown ${ }^{1}$ proposed a new type of conjugation, 'hyperconjugation', based on the fact that the heat of hydrogenation of an olefin is appreciably decreased by the presence of alkyl substituents on the unsaturated carbon atom. A necessary effect of hyperconjugation would be to change the lengths of the $\mathrm{C}-\mathrm{H}$ bond in the alkyl group and the $\mathrm{C}-\mathrm{C}$ bond adjacent to a double or triple bond. The $\mathrm{C}-\mathrm{Me}$ distance in toluene ${ }^{2}$ is $1.51 \AA$. and in methyl acetylene and acetonitrile ${ }^{3}$ it is $1.46 \AA$., compared with the normal C-C distance of $1.54 \AA$. in ethane. It was pointed out that part of these bond shortenings was due to the change in the atomic radius from tetrahedral to trigonal or digonal carbon and about one-half of the observed shortening was due to hyperconjugation.

Hyperconjugation was considered to be responsible for the dipole moment of alkyl benzenes. The ioniza. tion potentials of methylated ethylenes 4,5 and the absorption spectra ${ }^{5,6}$ were also given as evidence for hyperconjugation. The view that $\mathrm{C}-\mathrm{H}$ hyper conjugation is the predominant mode of electron release by alkyl substituents when attached to an electron-demanding system was originally proposed by Baker and Nathan as an explanation of certain rate and equilibrium data. The Baker-Nathan effect was in the order $\mathrm{Me}>\mathrm{E} t>i-\mathrm{Pr}>t-\mathrm{Bu}$, which is exactly the reverse of what one would expect if the electron release were by the inductive mechanism.

Although a great deal of physical and chemical evidence has been accumulated in support of the idea of hyperconjugation, recently there have been a number of observations which cannot be explained in a simple fashion by hyperconjugation, and the situation has become controversial.

Recent molecular structure investigations ${ }^{3,7}$ in several laboratories, on derivatives of acetonitrile and methyl acetylene, have conclusively shown that the length of a carbon-carbon single bond adjacant to a triple bond (that is, a bond between $s p$ and $s p^{3}$ carbon atoms) is always close to $1.46 \AA$., independent of the substituents on the $s p^{3}$ carbon. So it is concluded that the shortenings in the $\mathrm{C}-\mathrm{C}$ bonds between $s p$ and $s p^{3}$ carbon atoms $\left(0.08 \AA\right.$.) or $s p^{2}$ and $s p^{3}$ carbon atoms $(0.04 \AA$.) may not result from any kind of conjugation, and that it is likely that these bond contractions are entirely due to the changes in the covalent radius of carbon with hybridization. The bond-lengths in relation to hyperconjugation have been discussed in fair detail by Sutton ${ }^{8}$. The evidence for hyperconjugation from calorimetric data is no longer valid, since the change in the $\mathrm{C}-\mathrm{C}$ bond energies with bond-lengths (that is, with hybridization) was not taken into account in these calculations. So the effects attributed to hyperconjugation of the alkyl groups may equally be due to the introduction of a stronger $\mathrm{C}-\mathrm{C}$ bond. In general, the stabilization of an unsaturated system by alkyl substitution has been found to be essentially inde- pendent of the nature of the alkyl group and cannot be eccounted for in terms of steric effects ${ }^{9}$.

The evidence for hyperconjugation from dipole moment data also necds to be re-interpreted. Since the electronegativity of an $s p$ or $s p^{2}$ carbon is different from that of an $s p^{3}$ carbon, the resulting bonds (between any two differently hybridized carbon atoms) should have different polarities. In fact, Petro ${ }^{10}$ hes reported excellent agreement between the observed and calculated dipole moments of $\mathrm{C}-\mathrm{C}$ bonds between two differently hybridized carbon atoms. He concludes that hyperconjugation structures do not explain the non-zero dipole moment of toluene. Recently, Brown ${ }^{11}$ has studied the dipole moments of alkyl benzenes and the results are not conclusive.

The earlier evidence for hyperconjugation on the basis of ionization potentials and absorption spectra was not unambiguous because these deal with both the electronic ground-states and the excited states of molecules. The ionization potentials of the alkyl groups are actually found to be in the inductive order ${ }^{12}$. However, a simple molecular orbital treatment by Streitwieser and Nair ${ }^{13}$ seems to indicate that the methyl group can be treated as a 'heteroatom' donating two electrons to the $\pi$-system. The evidence from absorption spectra has met with a number of objections ${ }^{14-16}$. An explanation based on steric hindrance to solvation of the electron-deficient sites in the vicinity of the alkyl substituent has been suggested.

In general, it may be said that the effect of alkyl groups on the near ultra-violet absorption spectra of aromatic compounds is not consistent. A recent study of the $n \rightarrow \pi^{*}$ transitions of aliphatic ketones and nitro compounds in different types of solvents by Rao et al. ${ }^{17}$ seems to show the predominant role of resonance interaction of the alkyl groups in the excited states of these molecules. An earlier investigation by Rao, Goldman and Lurie ${ }^{18}$ of the infra-red carbonyl frequencies in aliphatic ketones had indicated that mainly inductive effects were important in the ground-states of these molecules.

The chemical evidence for hyperconjugation has been a subject of controversy. The Baker-Nathan order $\mathrm{Me}>\mathrm{Et}>i$ - $\mathrm{Pr}>t-\mathrm{Bu}$, has been found in a number of reactions and has been explained in terms of the $\mathrm{C}-\mathrm{H}$ hyperconjugation ${ }^{19}$. The importance of $\mathrm{C}-\mathrm{C}$ hyperconjugation in the $t$-butyl group has also been pointed out ${ }^{20}$. The relative importance of $\mathrm{C}-\mathrm{H}$ and $\mathrm{C}-\mathrm{C}$ hypereonjugation in aliphatic and aromatic series has been evaluated by the application of the linear inductive energy relationship 21,22 . McCaulay and Lien $^{23}$ have shown that $\mathrm{C}-\mathbf{H}$ hyperconjugation must be an important mode of electron release in the methyl-substituted aromatic cations. De la Mare $^{24}$ has discussed the possibility of $\mathrm{OH}$ and NH hyperconjugation. Shiner ${ }^{25}$, Lewis ${ }^{26}$ and Taft and co-workers ${ }^{27}$ have shown that hypercon- 